Int. J. Dev. Biol. 56: 583-591 (2012)

doi: $10.1387 / \mathrm{ijdb} .113454 \mathrm{ab}$

\title{
Hydra, a model system to trace the emergence of boundaries in developing eumetazoans
}

\author{
ANGELIKA BÖTTGER ${ }^{1}$ and MONIKA HASSEL ${ }^{*}, 2$ \\ ${ }^{1}$ Department of Biology 2, Ludwig-Maximilians-Universität München, Munich and \\ ${ }^{2} \mathrm{FB} 17$, Morphology and Evolution of Invertebrates, Philipps-Universität Marburg, Marburg, Germany
}

\begin{abstract}
In developing embryos, boundary formation between neighbouring groups of cells is essential to establish compartments which later fulfil specialized functions. The ability to form such boundaries has likely developed early in animal evolution - due to functional requirements imposed by the necessity to separate tissues which protect the animal, take up food or ensure propagation. Essential for boundary formation are local cues which may be provided by the intersection of diffusible molecules or set locally by activation of membrane-bound receptors and transcription factors. In the simple diploblastic Hydra, a representative of the basally branching metazoan Cnidaria, tissue boundaries are morphologically detectable between the body column and terminally differentiated head and foot structures. In adult polyps, these borders correspond to sharp lines of differential gene expression. They form de novo during regeneration and budding of a young polyp. Functional studies strongly suggest the involvement of FGFR/Notch signalling in the establishment of the parent-bud boundary, and it is very likely that these pathways interact with theWNT and BMP systems. How boundaries in the head and foot regions are generated is still unclear. Expression patterns of transcription factors like Cngsc, HyAlx, HyBra, HyOtx, Prdl-a, CnNK2 and Manacle show strong position dependency and may be involved in regulating gene expression on either side of the boundaries, by interpreting positional information during their formation and maintenance. Due to its simplicity, the easy accessibility to pharmacological interference and, recently, transgenesis, Hydra is an interesting prebilaterian model system to study the emergence of boundary-forming mechanisms during evolution.
\end{abstract}

KEY WORDS: boundary, evolution, Hydra, Notch, FGFR

\section{Introduction}

All multicellular animals with their diverse body plans develop from one fertilised egg. During embryonic development cells multiply and differentiate, and specialized structures emerge from fields or layers of cells, which are initially identical. Differential gene expression induced by signalling from within these fields and from the surrounding stabilises compartments necessary for the emergence of cells with different and mutually exclusive properties. The separation process requires formation of molecular and morphological boundaries, which prevent intermingling of cells with different destinies, allow stable expression of transcription factors in adjacent fields and often themselves function as new signalling centres to establish refined patterns within the respective domains (Sánchez-Camacho et al., 2005; Dahmann etal., 2011). Eventually adult animals are formed with their cells organised in tissues and organs physically separated from each other.

Boundary formation in multicellular animals has been described in a manifold of developmental contexts. Although the targets for signalling at boundaries and during their formation are diverse depending on the characteristics of the developing tissues, a number of signalling pathways have been recurrently found to be involved. In the following we will shortly introduce boundary-forming signal systems in vertebrates and insects, for which orthologues have been identified and partially characterised in Cnidaria and then summarize what is known in Hydra.

Abbreviations used in this paper: BMP, bone morphogenetic protein; FGF, fibroblast growth factor.

\footnotetext{
*Address correspondence to: Monika Hassel. FB 17, Morphology and Evolution of Invertebrates, Philipps-Universität Marburg, Karl von Frisch Str. 8 , D-35032 Marburg, Germany. Tel: ++49-6421-2823408. Fax: ++49-6421-2823407. E-mail: hassel@ biologie.uni-marburg.de

Web: http://www.uni-marburg.de/fb17/fachgebiete/zoologie_tierevo/index_html
}

Final, author-corrected PDF published online: 5 June 2012

ISSN: Online 1696-3547, Print 0214-6282

(C) 2012 UBC Press

Printed in Spain 


\section{Signalling between adjacent cells}

Of particular importance for the establishment of perfectly separated developmental compartments are the Notch and ephrin signalling pathways. Receptors and ligands of both pathways are membrane proteins. They either contain transmembrane domains as in the case of Notch, ephrin B and ephrin receptors (Eph), or are attached to the cell membrane, e.g. by GPI anchors, like the Atype ephrins (Bray 2006; Himanen et al., 2007). Signalling through both pathways therefore occurs between cells that are in direct contact, and it results in differential responses in adjacent cells. Best-known examples are the mutually exclusive differentiation programs started by Notch signalling in the nervous system or at tissue boundaries and the adhesive-anti-adhesive cycles controlled by Eph/ephrin signalling, which are essential for pathfinding of neurons and neural crest cells, for angiogenesis (Himanen et al., 2007; Pasquale 2008) or for the specification of cell layers during gastrulation (Rohani et al., 2011). Since Eph-ephrin signalling is bidirectional, both, signal sending and signal receiving cells, are instructed and thus able to respond differentially.

Our knowledge concerning the molecular mechanisms involved in boundary formation comes from investigations in bilaterian animals, especially in insects and in vertebrates. Very well described examples include the establishment of the dorsal/ventral boundary in the Drosophila wing (Kim et al., 1996) or segment boundaries of the Drosophila leg, which are established in imaginal discs of the larvae (de Celis et al., 1998). In vertebrates a lot of research has been invested into studying boundary formation between rhombomers of the developing brain and the establishment of segment boundaries (reviewed in Dubrulle and Pourquie, 2002).

In most of these instances Notch signalling has been shown to be involved. The molecular mechanisms are just emerging: Recently, in an elegant tissue culture model, Sprinzak and coworkers elucidated how the propagation of modest differences in the amount of Notch receptors and their ligands at membranes of adjacent cells by use of the intrinsic kinetic of cis- and trans-signalling responses can lead to amplification of the signals and thus the formation of defined regions of differential gene expression (Sprinzak et al., 2009; Sprinzak et al., 2011).

\section{Signalling involving diffusible molecules}

Directly cooperating with the immediate cell-to-cell signalling of Notch-and ephrin pathways, are FGF-and Wnt-signalling pathways (Takahashi etal., 2005). Both pathways depend on diffusible ligands and membrane-bound receptors and are thus able to integrate signals, which move across longer distances.

In contrast to Notch and ephrins, diffusible signals like FGF and Wnt, but also TGF $\beta /$ BMP, Shh or Dpp, define, at least initially, regions instead of sharp boundaries and they provide positional and local information. The intersections of diffusible signals may generate Cartesian coordinates and provide positional information for morphogenetic boundaries (Niehrs 2010). In this context, it is important to note that diffusible molecules may act as morphogens. Their concentration profile provides precise thresholds for transcription factor activity, which defines sharp boundaries within a graded morphogen distribution (Sánchez-Camacho etal., 2005). In the very complex organ systems of higher developed animals,
FGF, transforming growth factor- $\beta$ (TGF- $\beta$ ), Wnt and Shh were identified as potential morphogens and work in concert with Notch locally to define boundaries.

Although in principle freely diffusible, most known growth factors and morphogens underly restricted diffusion. Posttranslational modifications like lipidation limit the range of e.g. Wnt ligands. Moreover, Wnt, Shh and several of the 22 vertebrate FGFs, which are secreted in the interstitial space, are scavenged by heparan sulfate proteoglycans (HSPGs) of the extracellular matrix (ECM) (Häcker et al., 2005; Yu et al., 2009). Their controlled release from the ECM, is a regulatory option. HSPGs thus restrict the range of action of secreted growth factors and thereby may sharpen boundaries.

As exemplified by FGFs, growth factors may also be removed from a diffusion gradient by binding to their receptors and subsequent endocytosis of ligand-receptor complexes: following stoechiometric binding of FGF, two FGFR dimerize and autophosphorylate to achieve the activation of downstream signalling pathways. The receptor-ligand complex is subsequently internalized and either targeted to the lysosomal compartment for degradation - or to the recycling compartment. Provided FGF is available in limited amounts, its binding to the receptor generates a local "sink". In vertebrates, such a source - sink mechanism (= FGF release establishment of a gradient - capture and removal of FGF) has been demonstrated and discussed in the context of establishing the midbrain-hindbrain boundary (MHB)(Yu et al., 2009).

This boundary is a well-known example for interaction of FGF and WNT signalling systems. It is established and maintained by a combination of WNT1, FGF8 and transcription factor signalling: at the anterior margin Wnt1 and Otx2 expression domains are located, the posterior margin is precisely defined by FGF8 and Gbx2 domains (Acampora et al., 2001). Any change in their expression pattern or the diffusion range of Wnt1 or FGF8 ligands causes fatal effects in the developing brain. During evolution, a similar boundary seems to have existed already in the urbilaterian brain: Gbx2 and Otx2 are expressed at the interface between the Drosophila Deuto- and Tritocerebrum in a mutually exclusive manner. In the flour beetle Tribolium, besides gbxand otxalso Wnt1 and Tc-fgf8are expressed locally in the developing brain (Bolognesi et al., 2008). Thus, the boundary in the tripartite insect brain might correspond to the MHB in vertebrates (Hirth et al., 2003), but functional data are not yet available.

In summary, boundary formation can be achieved by local interaction, but also at the intersections of diffusible molecules or set by morphogen thresholds. This positional information will then be refined by secondary processes like local activation of growth factor receptors or transcription factors.

\section{Boundaries in prebilaterian animals}

Since boundaries are prerequisite to establish compartments specialized for different functions, and also to establish regionalization along one or more body axes, they occur already in prebilaterian animals like Hydra. Elucidation of the molecular mechanisms involved in their formation and maintenance is only at its beginning, but became easier with genome projects and the establishment of transgenic approaches (Steele 2002; Wittlieb et al., 2006; Chapman et al., 2010). 


\section{Tissue composition and dynamics in Hydra}

The cnidarian Hydra is a well-characterized representative of a prebilaterian. As detailed in other reports of this review series, its simple body plan comprises a head with tentacles and a mouth opening at the tip of a cone-shaped hypostome, a gastric column and a foot, consisting of a peduncle with a basal disc at its end (Fig. 1). Two single-celled epithelial layers surround the body and form the outer ectoderm (or epidermis) and the inner endoderm (or gastrodermis, see other reviews of this series). These epithelial cells are self-renewing. They constitute epithelio-muscular cells, with an apical epithelium-forming cell body and basal, bidirectionally oriented processes containing contractile fibres. Epithelio-muscular cells of the endoderm thus function as circular muscles, ectodermal ones as longitudinal muscles. Cells of both layers secrete an acellular, collageneous mesoglea, which corresponds to the extracellular matrix (ECM) of higher animals (Sarras 2012). The epithelial cells are anchored in and separated by this ECM (Zhang et al., 2007). In the interstitial spaces of both layers so-called interstitial cells reside, which harbour continuously self-renewing pluripotent stem cells and their differentiation products, such as nerve cells, nematocytes, gland cells and germ cells (David 2012; Hobmayer et al., 2012). All cells of the interstitial and the two epithelial cell lineages are constantly renewed by proliferation in the gastric column. In consequence, tissue is constantly displaced towards the terminally differentiated, non-proliferating tentacles and the basal disc (Fig.1). Additionally, mass tissue movement transfers gastric tissue into buds. These form regularly perpendicular to the parent body axis in well fed animals and constitute the means of asexual reproduction (reviewed in (Bode 1996). During budding, longitudinal and circular epithelial cell processes undergo massive rearrangement to match the new tissue orientation. The young polyp differentiates apical and basal structures and finally separates its epithelia from the parent having formed its own basal disc. Several marker genes for regional specification during growth and budding in Hydra have been described (Steele 2012). Tissue properties and gene expression patterns have been used to establish mathematical models for Hydra patterning (Meinhardt 2012).

\section{Boundaries in Hydra and state-of-the-art of molecular mechanisms involved in their establishment}

The Hydra body is subdivided by several morphologically distinguishable boundaries, which all correlate to molecular boundaries (Fig. 1). From top to bottom these boundaries are (i) the ectoendodermal boundary at the hypostome tip (mouth opening), where both tissues are in direct contact. (ii) The hypostome - tentacle boundary, where proliferating hypostomal cells meet the protruding and terminally differentiating ectodermal battery cells and flat endodermal epithelio-muscular cells (Fig.1A, red line). (iii) The tentacle - body column boundaries (grey and blue in Fig. $1 \mathrm{~A}$ ) where proliferating ectodermal epithelio-muscular cells differentiate into battery cells which take up mature nematocytes with their cysts by transendocytosis. (iv) The body-peduncle boundary located right

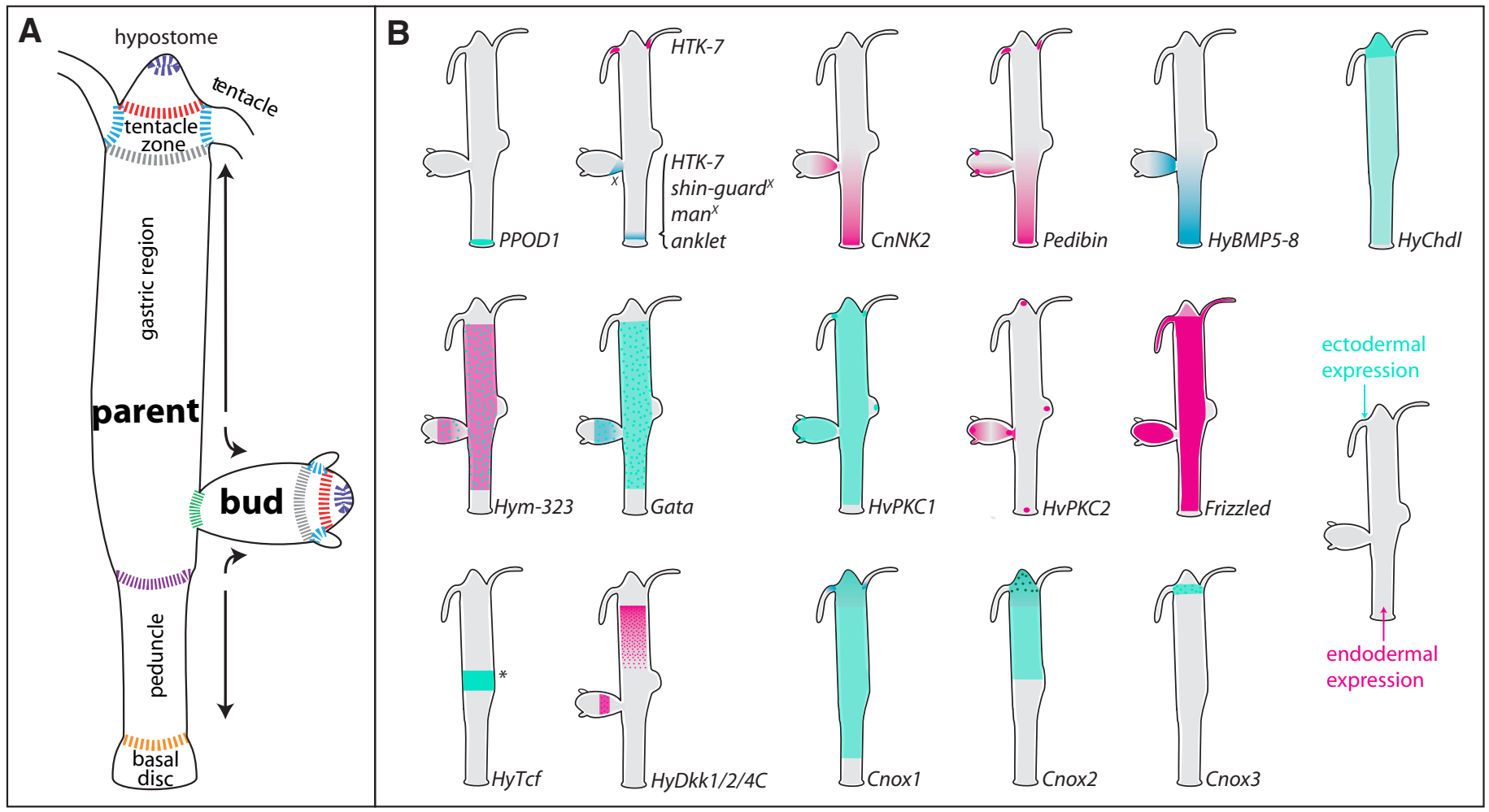

Fig. 1. Schematic overview of morphological boundaries, mass tissue movement and gene expression domains. (A) Morphological boundaries. (B) Selected expression boundaries of genes in adult Hydra. Dots indicate that only a certain population of epithelial cells (Hym-323, Gata, Cnox2 and Cnox3) or of gland cells (HyDkk1/2/4C) express the gene. The asterisk indicates that HyTcf is expressed transiently in the budding competent zone prior to bud evagination. Shin guard and manacle are expressed asymmetrically in the early developing bud (x). 
below the budding zone. This boundary is not visible equally well in every Hydra strain. It marks a decrease in the diameter of the upper body column and the appearance of big, translucent ecto- and entodermal cells. (v) The peduncle -basal disc boundary, where proliferating ecto- and endodermal epithelio-muscular cells differentiate into mucous-secreting basal disc cells. (vi) In bud-producing animals, the region from which parent tissue is recruited into the bud protrusion is separated from the parent animal by a morphologically hardly visible boundary (green line in Fig. 1A), When the bud has finished its growth, this boundary becomes very sharp and defines the position, where the bud foot forms and complete separation from parent tissue occurs.

Due to the tissue dynamics of Hydraand the stem cell properties of its three cell lineages, patterning signals are constantly active in the adults. This obviously includes permanent signalling at the tissue boundaries, and it causes the almost unlimited capacity of Hydra for regeneration. During budding and regeneration of adult polyps boundaries have to be formed de novo.

In the following, we will summarize which marker genes and signalling components are expressed at the major tissue boundaries (and compartments) in Hydra and what is known about boundary-related signalling pathways.

\section{Head and upper body region}

The Hydra head consists of a hypostome and mouth opening in its center plus a whorl of tentacles below. Specific gene expression domains surrounding the hypostome can be observed in only a couple of cells at the very tip, in broader rings or in the whole region between mouth opening and the lower tentacle border. Fig. 1B and Fig. 2 give an overview of expression zones within the Hydra head and body column for genes expressed in epithelial cells of the ecto- and entodermal layer as well as, in one case $(H y D k k)$ in gland cells. These gene expression patterns in adult polyps suggest an astonishingly complex regionalization of the Hydra body, which contrasts the morphological simplicity of the animals.

Since expression in stage 9 of bud development mostly corresponds to the pattern found in adult polyps, the following also referes to patterns shown in Fig. 2 for bud development.

At the very tip of adult polyps and buds, HvPKC2, an $\varepsilon$-type PKC encoding gene (Hassel et al., 1998) and several Wnt pathway genes are strongly expressed (Lengfeld et al., 2009). The smallest expression zone is covered by Wnt3 (Fig. 2), which encompasses only 8-9 cell diameters and is present in both, the ecto- and the endodermal epithelium. Slightly beyond this Wnt3 zone reaches expression of the Wnt-targeted transcription factor, HyTcf (Hobmayer et al., 2000). An even larger area including the entire hypostome and almost touching the bases of tentacles is covered by HyBra expression (Technau and Bode 1999), its expression domain overlaps with HyWnt7 (Lengfeld et al., 2009) and transcription factors like budhead and prdl-a (Martinez et al., 1997; Gauchat et al., 1998; Takahashi et al., 2005). The region where hypostome cells proliferate is marked by the expression of budhead, which is lacking underneath the proliferative region, but is present again in the space between the tentacles.

Especially striking is the expression of the transcription factor goosecoid (Cngsc, Fig. 2). It is found only in non-tentacle cells and the apical-most hypostomal cells, thus comprising a two-stripe pattern (Broun et al., 1999). These stripes mark morphologically invisible boundaries and seem to correspond to the expression borders of Wnt genes.

At the boundary between tentacles and body column (Fig. 1) proliferating epithelial tissue impinges on tissue made of nonproliferating battery cells. These huge cells have transdifferentiated from body column epithelio-muscular cells and take up mature nematocytes (stinging cells) by transendocytosis.

Genes, which demarcate the basal end of the tentacles and thus the boundary between these two tissues include HyDsh, HvWnt8 and Hmfz2 (Fig. 2) (Minobe et al., 2000; Philipp et al., 2009). A role for non-canonical Wnt in mediating tentacle evagination has been shown recently. Co-expression of BMP5-8b moreover indicates a localized role of BMP and Wnt signalling, which might be complex. Strong expression of a Hydra Chordin-like-encoding gene (HyChdl, Fig. 1B), a putative antagonist of BMP-signalling, furthermore suggests fine-tuned regulation (Reinhardt et al., 2004; Rentzsch et al., 2007). Potential transcriptional regulators at this boundary are the transcription factors CnOtx, HyAlx, Budhead and Prdl-a (Martinez et al., 1997; Gauchat et al., 1998; Smith et al., 1999; Smith et al., 2000).

Unclear is the function of the two epitheliopeptides Hym301 and Pedibin (Takahashi et al., 2005), the role of the RTK Lemon in endodermal basal tentacle cells and in a broader region PKC1 (Hassel et al., 1998; Miller and Steele 2000), as well as that of the Hydra-specific unusual RTK Sweet Tooth, which is characterised by an extracellular lectin domain (Reidling et al., 2000). The whole tentacle region is demarcated by scattered expression of the transcription factor Cnox3 in epithelial cells (Gauchat et al., 2000). The endodermal tentacle tissue expresses the Hydra metalloprotease, HMMP, (Fig. 2), which is only weakly expressed in the endoderm of adjacent non-tentacle tissue (Leontovich et al., 2000; Sarras 2012).

In the tissue below the tentacles towards the body column, cells are proliferating. Whole-mount BrdU-labelling (Holstein et al., 1991) as well as the upper expression border of Gata, a transcription factor (Nakamura et al., 2011), mark this boundary.

In summary, the boundaries between tentacles, tentacle zone and hypostome are clearly marked. The apical end of the polyps contains several molecular boundaries surrounding the mouth opening and exemplified by the Cngsc stripes of expression (Fig. 2). The target genes for the transcription factors Cngsc, HyAlx, CnOtx and Cnox3, remain to be elucidated.

\section{Upper body - de novo establishment}

When a new head is formed by regeneration, the hypostomespecific genes Wnt3a and HyBra are initially expressed together with tentacle-specific and boundary-specific genes like HMMP, $H y A l x$ and $C n g s c$ in a diffuse cap covering the regenerating tip (Broun et al., 1999; Smith et al., 2000). Only at later stages their expression zones become separated - particularly conspicuous in the case of Cngsc. It is interesting to note that the two Cngsc expression domains in contrast develop successively during budding (see below). Separation of expression domains from a uniform early field requires mechanisms for de novo formation of the gene expression boundaries in the head. Preliminary results suggest that Notch signalling is involved in this process (Münder et al., in preparation). 


\section{Lower body region}

The basal end of Hydra where proliferating peduncle cells and non-proliferating differentiated basal disc cells meet shows a clear morphological and molecular boundary between basal disc and

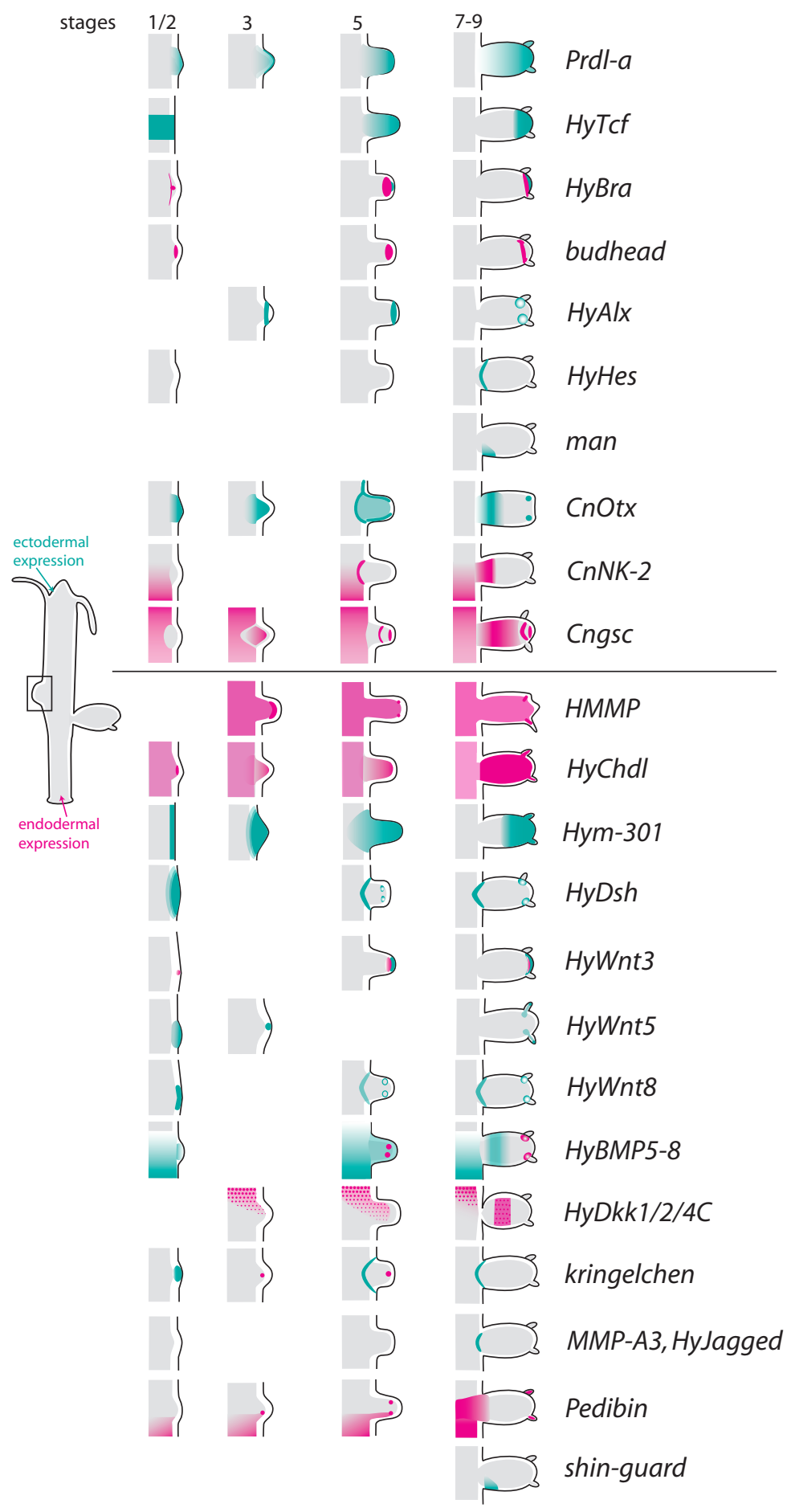

Fig. 2. Schematic representation of expression domains and boundaries in the developing bud. The upper part summarizes transcription factor expression domains, the lower one those of (diffusible) signalling elements, receptors and proteases. peduncle (Fig. 1B). Expression of the receptor tyrosine kinase shin-guard, the paired like homeobox gene manacle and the Hydra insulin receptor homolog HTK7 (Steele et al., 1996; Bridge et al., 2000) as well as anklet, a gene encoding a novel, secreted perforin-EGF-domain protein (Amimoto et al., 2006) define this boundary by a narrow expression zone.

As expected for the transition zone towards a terminally differentiated zone, the peduncle - basal disc boundary is marked also by gene expression regions, which are either excluded from the basal disc or expressed exclusively there. $P P O D 1$, for example, is restricted to the basal disc (Fig. 1B) and PPOD2 appears in cells directly adjacent to peduncle cells (Hoffmeister-Ullerich et al., 2002; Thomsen and Bosch 2006). Moreover the basal disc has a very high level of peroxidase activity, which also clearly separates it from adjacent peduncle cells (Hoffmeister and Schaller 1985). Recent results have shown that PPODs encode extracellular lectins and not peroxidases (Pauly etal., 2007) (Böttger et al., in preparation). Like in the hypostome tip, HvPKC2 expression, is found in a small group of cells in the central basal disc endoderm (Hassel et al., 1998), indicating that this PKC is a good marker for the extreme positional values in the Hydra body (Fig. 1B).

Excluded from the basal disc but expressed in and above the peduncle are the genes sweet tooth, encoding an atypical RTK (Reidling et al., 2000), the serine-threonine kinase HvPKC1 (Hassel et al., 1998), BMP5-8b (Reinhardt et al., 2004) and Frizzled (Minobe et al., 2000). pedibin, encoding a foot-formation-promoting peptide, CnNK2 and BMP5-8b show expression fading out towards the budding region right above the peduncle (Grens et al., 1999; Hoffmeister-Ullerich 2001; Reinhardt et al., 2004).

In short distance above the sharp peduncle-basal disc boundary, a morphologically unrecognizable border is revealed (Fig. 1B) by the expression boundaries of Gata, Hym323 and Cnox1 (Gauchat et al., 2000; Takahashi et al., 2005; Takahashi and Fujisawa 2009; Nakamura et al., 2011). This diffuse boundary zone seems to correlate with the lower end of the proliferation zone.

A little higher up the body column in the mid-body region, expression domains of the upper and in the lower body half meet as exemplified by CnNK2, Pedibin, HyBMP5-8b, prdl-a and HyDkk1/2/4C expression (Grens et al., 1996; Gauchat et al., 1998; Hoffmeister-Ullerich et al., 2002; Reinhardt et al., 2004; Augustin et al., 2006) (Fig. 2). This border is, again, not a sharp one, nevertheless, the region is extremely interesting with respect to morphogenesis: the budding region (see below) is located here. HyTcf, the Wnt target transcription factor, marks the budding-competent girdle shortly before a bud begins to evaginate. Increasing expression of the transcription factor prdl-A (Gauchat et al., 1998) and the anti-Wnt HyDkk1/2/4C (Augustin et al., 2006) demarcate the region as well.

\section{Lower body region - de novo establishment}

During foot regeneration, the boundary separating basal disc and peduncle has to be formed the novo. Manacle is initially expressed in a diffuse cap formed by the regenerating tissue and its expression is only later restricted to the boundary between basal disc and peduncle. At the same time shin-guard 
expression is initiated precisely at this border region (Bridge et al., 2000). PPOD1 and HVPKC2, which will later be restricted to different regions in the basal disc, are also expressed very early at the tips of foot regenerates. The same is true for HyBMP5-8b, which in contrast to the other two genes is excluded from basal disc cells in mature feet. Thus, similar to head regenerates, genes, which belong to different parts of the final foot, are co-expressed in early regenerating feet and separated only later.

\section{Budding}

During budding continuously proliferating tissue of the body column is recruited into the bud. The initially observed thickening of the ectoderm can be noticed morphologically as a placode. By ectodermal India ink labelling it became obvious that Hydra vulgaris tissue marking a concentric ring on the parent animal is recruited: cells in the centre of this ring were shown to later become hypostome whereas cells at the outer circle end up at the basal end of the bud (Otto and Campbell 1977). Except for the ectodermal cells right above or below the bud, all other cells in this region have to change the orientation of muscle fibres. At final stages of this process the bud base constricts and forms a basal disk. Its connection with the parent becomes increasingly smaller until it detaches.

A defined morphological boundary between the early bud and parent cells cannot be observed. However, before first signs of evagination are visible, a molecular boundary defines the buddingcompetent zone (Fig. 1B, Fig. 2): the Wnt pathway genes HyTcfand $\beta$-catenin are expressed in a broad band covering the region were buds will evaginate (Hobmayer et al., 2000). Once bud evagination begins, head specific genes including Wnt3a and HyBra are expressed in the centre of the protruding placode (Technau and Bode 1999). Tentacle specific genes are also expressed, but they either only appear transiently $(H y A / x)$ or extend in concentric zones around the centre (budhead, HyDsh, Hmfz2, HyWnt8 and HMMP (Martinez et al., 1997; Leontovich et al., 2000; Smith et al., 2000; Siebert et al., 2005; Philipp et al., 2009).

Almost the whole region from which cells will later be found in the bud is marked by expression of CnOtx, prdl-a and Hym301 (Fig. 2) at budding stage 3 (Gauchat et al., 1998; Smith et al., 1999; Takahashi et al., 2005). However, the boundary between early Cnotx-, prdl-a- and Hym301-positive and -negative tissue is not very sharp. These genes roughly mark the region of the bud's body column, which will be defined after completion of bud morphogenesis through sharp boundaries apically towards the tentacles and basally towards the foot tissue. At stage 7-8, when morphogenesis begins, CnOtx clearly marks the body-tentacle boundary as well as the basal end of the bud in relatively broad stripes of gene expression.

The homeobox gene $C n N K-2$, is expressed below the budding zone in adult animals and also at the basal end of progressed bud stages (Fig. 1B, Fig. 2). It is conspicuously absent from the early bud. This indicates that the basal tissue of a bud is not defined early on. CnNK-2 is actually only upregulated in the last set of endodermal cells, which migrates into the bud around stage 6 and ends up in the stalk and basal-most cells of the bud. It appears that a sharp boundary of the bud towards the parent is not clearly determined at the beginning of budding (Siebert et al., 2005). It rather forms late at budding stage 7-8.
The earliest gene demarcating the parent-bud boundary is the Hydra FGFR kringelchen, which becomes upregulated in a ring, 5-6 cells broad and surrounds the bud base from stage 4 onwards. kringelchen marks varying populations of cells while they pass this boundary rather than a certain group of cells. Only late during bud formation, around budding stage 7-8, kringelchen expression is refined into a sharp ring which appears to indicate the boundary separating bud and parent tissue. At this point a number of additional genes change their expression zones from diffuse rings into sharp lines. These include HyDsh and HyWnt8 (Philipp et al., 2009), which are most probably expressed adjacent to each other. Just when these sharp lines of gene expression are produced, HyHes, encoding a target transcription factor of the Notch signalling pathway, is expressed transiently in a single-cell band immediately adjacent to kringelchen. At the same time the metalloprotease MMP-A3 is expressed in the kringelchen positive cells (Münder et al., 2010). From now on, kringelchen, MMP-A3, $H y D s h$ and HyJagged expression are restricted to parent tissue whereas foot specific genes are expressed in the newly forming bud peduncle (Sudhop et al., 2004; Prexl et al., 2011). Interestingly, HyWnt-8 is expressed in cells confining the peduncle at the side of the bud (Philipp et al., 2009).

These data strongly suggests that Notch/Wnt and FGF- signalling pathways are involved in the formation of the parent-bud boundary.

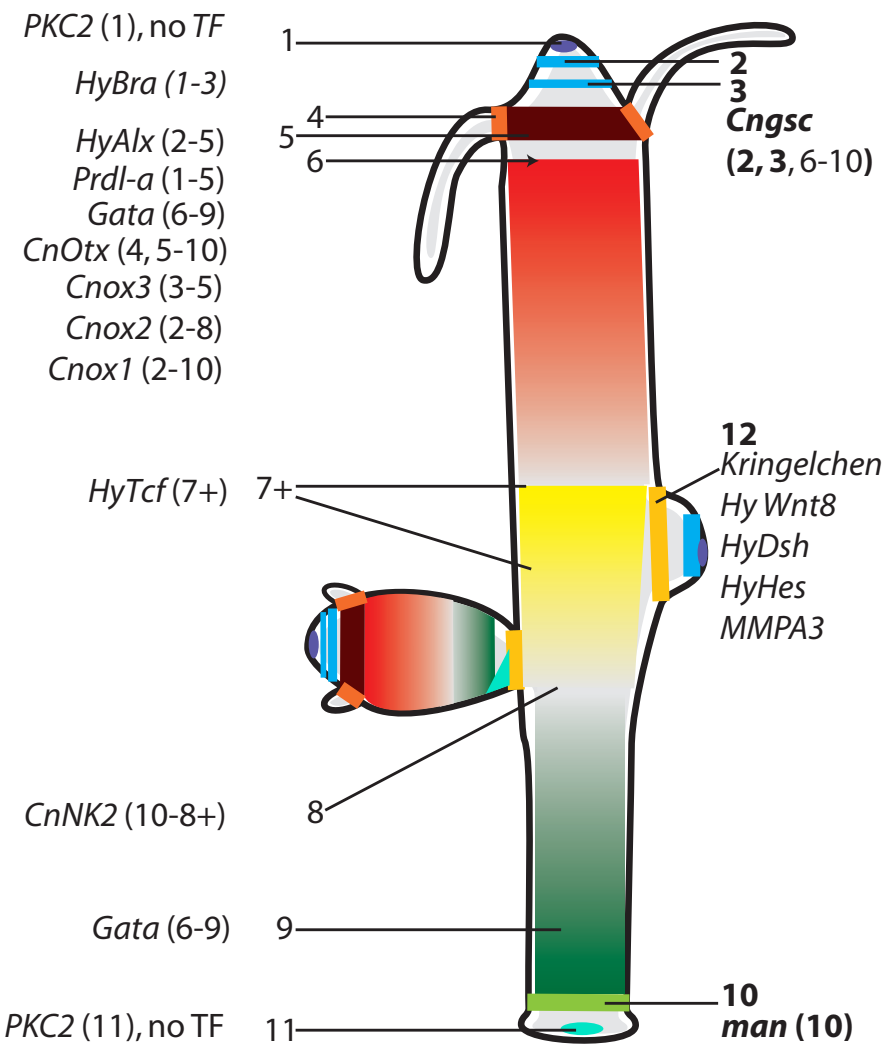

Fig. 3. Summary of epithelial gene expression domains and defined boundaries in Hydra. All boundaries identified by either a sharp line of marker gene expression (right side) or putative boundaries deduced from differential expression zones were numbered. The numbers in brackets indicate, at or between which of these boundaries certain transcription factors are expressed. 


\section{FGFR/Notch signalling controls the establishment of the bud-parent boundary}

Support for the hypothesis that FGFR/Wnt/Notch signalling are essential for the establishment of the parent-bud boundary comes from pharmacological inhibition experiments. Inhibition of FGFRsignalling with SU5402 and Notch-signalling with DAPT perturbs bud morphogenesis (Sudhop etal., 2004; Münder et al., 2010). Both inhibitors cause the expression zones of kringelchen and HyDsh to completely diffuse. As a consequence the buds fail to form feet and never detach, which yields two-headed, so-called Y-animals. Interestingly, such animals can also be obtained when Src (Fabila et al., 2002) and other potential targets for FGFR signalling are inhibited. Moreover, it is also seen as a result of $\mathrm{LiCl}$ treatment, which may increase either Wnt-signalling by inhibition of GSK-3 $\beta$ or impair PKC/inositol phosphate/calcium signalling and thereby disturb the boundary by shifting the balance of gene expression (Hassel et al., 1993; Fabila et al., 2002). This hypothesis has not been tested experimentally, yet. The expression data (and pharmacological inhibition) clearly show that boundary formation during budding in Hydra relies on Notch and FGFR signalling. Deduced from co-expression data it potentially also involves crosstalk with non-canonical Wnt signalling and HyWnt8.

In summary, a very likely candidate to establish the bud-parent boundary is, like in many other animals, the Notch pathway. Hydra has all major components for bona fide Notch signalling including a well conserved Notch receptor (HvNotch), a putative Notch ligand HyJagged (Prexl et al., 2011), components of the $\gamma$-secretase complex including presenilin, metalloproteases of the ADAM family (Kasbauer et al., 2007; Münder et al., 2010). Genes encoding $\mathrm{Su}(\mathrm{H})(\mathrm{CBF})$ and the transcriptional repressor HyHes have been identified as well as modulators of Notch signalling such as Fringe and Numb. It was also shown that the signalling mode in the Notch pathway, which is characterised by a regulated intra-membrane proteolysis mediated by metalloproteases of the ADAM family and presenilin, is conserved. $\mathrm{Su}(\mathrm{H})$ binding sites have been identified in the HyHes promoter and it was demonstrated that this promoter responds to NotchICD. Finally, the presenilin inhibitor DAPT is able to inhibit Notch-signalling in hydra cells by blocking the release of NICD from the membrane. Using this inhibitor a role for Notch signalling in interstitial stem cell differentiation was demonstrated (Kasbauer et al., 2007).

\section{What about ephrin signalling?}

Genes encoding ephrin receptors have only recently been identified in the genome and as ESTs in Hydra (Reddy et al., 2011). Unpublished results suggest that two of these genes are expressed at the base of the Hydra bud. Moreover, two genes encoding ephrins have also been found, but functional data are not available yet (Tischer and Böttger, unpublished). It will be very interesting to see how and where these molecules act in an organism, which lacks a blood circulation system and in which the nerve net is not visibly centralized.

\section{General considerations and perspectives}

The simple Hydra body is subdivided by a few, morphologically distinguishable, boundaries in the head and foot region. On a mo- lecular level a complex sub-regionalization and additional borders become visible (Fig. 3).

Sharp boundaries in adult Hydra are characterised by mutually exclusive gene expression on either side. Examples are Cngsc in the hypostome (boundaries 2 and 3 in Fig. 3), manacle and PPOD at the basal disc (boundary 10) and kringelchen/HyHes at the buds base (boundary 12). When the corresponding boundaries are formed de novo, in each case, an initial overlap of gene expression zones, which are later separated, is observed. This sequence of events appears as a particularly simple case of creating tissue boundaries.

Differential expression of signalling molecules including BMP5-8b, Wnt-8 and receptors for FGF and insulin indicate that these molecules might either define intersections for boundary formation or organise the tissue on either side of the boundaries. In agreement with such a view, the transient expression of HyTcf in the budding competent girdle (border region 7+ in Fig. 3) might depend on transiently forming intersections. Notch and FGFR signalling are clearly involved in forming the sharp boundary between bud and parent (Münder et al., 2010; Prexl et al., 2011), a role of ephrin signalling is likely.

In summary, the molecular pathways which are used in all higher animals to form tissue boundaries during development are not only present in prebilaterian animals but have already been recruited for similar tasks. The indicated simplicity of the Hydra system provides an ideal background to further elucidate the cellular and molecular mechanisms controlling the separation of initially identical (embryonic) tissue domains, which is the prerequisite to later form structures of high complexity.

\section{Acknowledgements}

We thank Katja Gessner and S. Münder for skillful help with the figures and Bert Hobmayer for critical reading of the manuscript. Our FGFR-and Notch- research was supported by research grants from the DFG (Ha 1732/10 and 11; BO1748-1 and BO1748-5).

\section{References}

ACAMPORA, D., BOYL, P. P., MARTINEZ-BARBERA, J. P., ANNINO, A., SIGNORE, M. and SIMEONE, A. (2001). Otx genes in evolution: are they involved in instructing the vertebrate brain morphology? J Anat 199: 53-62.

AMIMOTO, Y., KODAMA, R. and KOBAYAKAWA, Y. (2006). Foot formation in Hydra: a novel gene, anklet, is involved in basal disk formation. Mech Dev 123: 352-361.

AUGUSTIN, R., FRANKE, A., KHALTURIN, K., KIKO, R., SIEBERT, S., HEMMRICH, G. and BOSCH, T. C. (2006). Dickkopf related genes are components of the positional value gradient in Hydra. Dev Biol 296: 62-70.

BODE, H. R. (1996). The interstitial cell lineage of hydra: A stem cell system that arose early in evolution. J. Cell Sci. 109: 1155-1164.

BOLOGNESI, R., BEERMANN, A., FARZANA, L., WITTKOPP, N., LUTZ, R., BALAVOINE, G., BROWN, S. J. and SCHRÖDER, R. (2008). Tribolium Wnts: evidence for a larger repertoire in insects with overlapping expression patterns that suggest multiple redundant functions in embryogenesis. Dev Genes Evol 218: 193-202.

BRAY, S. J. (2006). Notch signalling: a simple pathway becomes complex. Nat Rev Mol Cell Biol 7: 678-689.

BRIDGE, D., STOVER, N. and STEELE, R. (2000). Expression of a novel receptor tyrosine kinase gene and a paired-like homeobox gene provides evidence of differences in patterning at the oral and aboral ends of hydra. Dev Biol220:253-262.

BROUN, M., SOKOL, S. and BODE, H. R. (1999). Cngsc, a homologue of goosecoid, participates in the patterning of the head, and is expressed in the organizer region of Hydra. Development 126: 5245-5254

CHAPMAN, J. A., KIRKNESS, E. F., SIMAKOV, O., HAMPSON, S. E., MITROS, T., WEINMAIER, T., RATTEI, T., BALASUBRAMANIAN, P. G., BORMAN, J., BUSAM, 
D. et al. (2010). The dynamic genome of Hydra. Nature 464: 592-596.

DAHMANN, C., OATES, A. C. and BRAND, M. (2011). Boundary formation and maintenance in tissue development. Nat Rev Genet 12: 43-55.

DAVID, C.N. (2012). Interstitial stem cells in Hydra: multipotency and decision-making. Int J Dev Biol 56: 489-497.

DE CELIS, J. F., TYLER, D. M., DE CELIS, J. and BRAY, S. J. (1998). Notch signalling mediates segmentation of the Drosophila leg. Development 125: 4617-4626.

DUBRULLE, J. and POURQUIE, O. (2002). From head to tail: links between the segmentation clock and antero-posterior patterning of the embryo. Curr Opin Genet Dev 12: 519-523.

FABILA, Y., NAVARRO, L., FUJISAWA, T., BODE, H. and SALGADO, L. (2002). Selective inhibition of protein kinases blocks the formation of a new axis, the beginning of budding, in Hydra. Mech Dev 119: 157-164.

GAUCHAT, D., KREGER, S., HOLSTEIN, T. and GALLIOT, B. (1998). prdl-a, a gene marker for hydra apical differentiation related to triploblastic paired-like headspecific genes. Development 125: 1637-1645.

GAUCHAT, D., MAZET, F., BERNEY, C., SCHUMMER, M., KREGER, S., PAWLOWSKI, J. and GALLIOT, B. (2000). Evolution of Antp-class genes and differential expression of Hydra Hox/paraHox genes in anterior patterning. Proc Natl Acad Sci USA 97: 4493-4498.

GRENS, A., GEE, L., FISHER, D. A. and BODE, H. R. (1996). CnNK-2, an NK-2 homeobox gene, has a role in patterning the basal end of the axis in hydra. Dev. Biol. 180: 473-488.

GRENS, A., SHIMIZU, H., HOFFMEISTER, S. A. H., BODE, H. R. and FUJISAWA, T. (1999). The novel signal peptides, pedibin and Hym-346, lower positional value thereby enhancing foot formation in hydra. Development 126: 517-524.

HÄCKER, U., NYBAKKEN, K. and PERRIMON, N. (2005). Heparan sulphate proteoglycans: the sweet side of development. Nat Rev Mol Cell Biol 6: 530-541.

HASSEL, M., ALBERT, K. and HOFHEINZ, S. (1993). Pattern-Formation in HydraVulgaris Is Controlled by Lithium-Sensitive Processes. Dev. Biol. 156: 362-371.

HASSEL, M., BRIDGE, D., STOVER, N., KLEINHOLZ, H. and STEELE, R. (1998). The level of expression of a protein kinase $C$ gene may be an important component of the patterning process in Hydra. Dev Genes Evol 207: 502-514.

HIMANEN, J. P., SAHA, N. and NIKOLOV, D. B. (2007). Cell-cell signaling via Eph receptors and ephrins. Curr Opin Cell Biol 19: 534-542.

HIRTH, F., KAMMERMEIER, L., FREI, E., WALLDORF, U., NOLL, M. and REICHERT, $\mathrm{H}$. (2003). An urbilaterian origin of the tripartite brain: developmental genetic insights from Drosophila. Development 130: 2365-2373.

HOBMAYER, B., JENEWEIN, M., EDER, D., GLASAUER, S., GUFLER, S., HARTL, M. and SALVENMOSER, W. (2012). Stemness in Hydra - a current perspective. Int J Dev Biol 56: 509-517.

HOBMAYER, B., RENTZSCH, F., KUHN, K., HAPPEL, C., VON LAUE, C., SNYDER, P., ROTHBÄCHER, U. and HOLSTEIN, T. (2000). WNT signalling molecules act in axis formation in the diploblastic metazoan Hydra. Nature 407: 186-189.

HOFFMEISTER, S. A. H. and SCHALLER, H. C. (1985). A new biochemical marker for foot-specific differentiation in hydra. Roux's Arch. Dev. Biol. 194: 453-461.

HOFFMEISTER-ULLERICH, S. A. (2001). The foot formation stimulating peptide pedibin is also involved in patterning of the head in hydra. Mech Dev 106: 37-45.

HOFFMEISTER-ULLERICH, S. A., HERRMANN, D., KIELHOLZ, J., SCHWEIZER, M. and SCHALLER, H. C. (2002). Isolation of a putative peroxidase, a target for factors controlling foot-formation in the coelenterate hydra. Eur. J. Biochem. 269: 4597-4606.

HOLSTEIN, T., HOBMAYER, E. and DAVID, C. (1991). Pattern of epithelial cell cycling in hydra. Dev Biol 148: 602-611.

Kasbauer, T., TOWB, P., AleXandrova, O., DAVID, C. N., DALl'ARMI, E., STAUDIGL, A., STIENING, B. and BOTTGER, A. (2007). The Notch signaling pathway in the cnidarian Hydra. Dev. Biol. 303: 376-390.

KIM, J., SEBRING, A., ESCH, J. J., KRAUS, M. E., VORWERK, K., MAGEE, J. and CARROLL, S. B. (1996). Integration of positional signals and regulation of wing formation and identity by Drosophila vestigial gene. Nature 382: 133-138.

LENGFELD, T., WATANABE, H., SIMAKOV, O., LINDGENS, D., GEE, L., LAW, L., SCHMIDT, H., OZBEK, S., BODE, H. and HOLSTEIN, T. (2009). Multiple Wnts are involved in Hydra organizer formation and regeneration. Dev Biol 330: 186-199.

LEONTOVICH, A. A., ZHANG, J. S., SHIMOKAWA, K., NAGASE, H. and SARRAS, M. P. (2000). A novel hydra matrix metalloproteinase (HMMP) functions in extra- cellular matrix degradation, morphogenesis and the maintenance of differentiated cells in the foot process. Development 127: 907-920.

MARTINEZ, D., DIRKSEN, M., BODE, P., JAMRICH, M., STEELE, R. and BODE, H. (1997). Budhead, a fork head/HNF-3 homologue, is expressed during axis formation and head specification in hydra. Dev Biol 192: 523-536.

MEINHARDT, H. (2012) Modeling pattern formation in hydra: a route to understanding essential steps in development. Int. J. Dev. Biol. 56: 447-462.

MILLER, M. A. and STEELE, R. E. (2000). Lemon encodes an unusual receptor protein-tyrosine kinase expressed during gametogenesis in Hydra. Dev. Biol. 224: 286-298.

MINOBE, S., FEI, K., YAN, L., SARRAS JR, M. and WERLE, M. (2000). Identification and characterization of the epithelial polarity receptor "Frizzled" in Hydra vulgaris. Dev Genes Evol 210: 258-262.

MÜNDER, S., KÄSBAUER, T., PREXL, A., AUFSCHNAITER, R., ZHANG, X., TOWB, P. and BÖTTGER, A. (2010). Notch signalling defines critical boundary during budding in Hydra. Dev Biol 344: 331-345.

NAKAMURA, Y., TSIAIRIS, C. D., ÖZBEK, S. and HOLSTEIN, T. W. (2011). Autoregulatory and repressive inputs localize Hydra Wnt3 to the head organizer. Proc Natl Acad Sci USA 108: 9137-9142.

NIEHRS, C. (2010). On growth and form: a Cartesian coordinate system of Wnt and BMP signaling specifies bilaterian body axes. Development 137: 845-857.

OTTO, J. and CAMPBELL, R. (1977). Budding in Hydra attenuata: bud stages and fate map. J Exp Zool 200: 417-428.

PASQUALE, E. B. (2008). Eph-ephrin bidirectional signaling in physiology and disease. Cell 133: 38-52.

PAULY, B., LASI, M., MACKINTOSH, C., MORRICE, N., IMHOF, A., REGULA, J., RUDD, S., DAVID, C. N. and BOTTGER, A. (2007). Proteomic screen in the simple metazoan Hydra identifies 14-3-3 binding proteins implicated in cellular metabolism, cytoskeletal organisation and $\mathrm{Ca} 2+$ signalling. BMC Cell Biol. 8: 31 .

PHILIPP, I., AUFSCHNAITER, R., OZBEK, S., PONTASCH, S., JENEWEIN, M., WATANABE, H., RENTZSCH, F., HOLSTEIN, T. W. and HOBMAYER, B. (2009), Wnt/beta-Catenin and noncanonical Wnt signaling interact in tissue evagination in the simple eumetazoan Hydra. Proc. Natl. Acad. Sci. USA 106: 4290-4295.

PREXL, A., MUNDER, S., LOY, B., KREMMER, E., TISCHER, S. and BOTTGER, A. (2011). The putative Notch Ligand HyJagged is a transmembrane protein present in all cell types of adult hydra and upregulated at the boundary between bud and parent. BMC Cell Biology 12: 38.

REDDY, P. C., BIDAYE, S. S. and GHASKADBI, S. (2011). Genome-wide screening reveals the emergence and divergence of RTK homologues in basal Metazoan Hydra magnipapillata. J Biosci 36: 289-296.

REIDLING, J. C., MILLER, M. A. and STEELE, R. E. (2000). Sweet Tooth, a novel receptor protein-tyrosine kinase with $\mathrm{C}$-type lectin-like extracellular domains. $J$ Biol Chem 275: 10323-10330.

REINHARDT, B., BROUN, M., BLITZ, I. L. and BODE, H. R. (2004). HyBMP5-8b, a BMP5-8 orthologue, acts during axial patterning and tentacle formation in hydra. Dev Biol 267: 43-59.

RENTZSCH, F., GUDER, C., VOCKE, D., HOBMAYER, B. and HOLSTEIN, T. W. (2007). An ancient chordin-like gene in organizer formation of Hydra. Proc Natl Acad Sci USA 104: 3249-3254.

ROHANI, N., CANTY, L., LUU, O., FAGOTTO, F. and WINKLBAUER, R. (2011). EphrinB/EphB signaling controls embryonic germ layer separation by contactinduced cell detachment. PLoS Biol 9: e1000597.

SÁNCHEZ-CAMACHO, C., RODRÍGUEZ, J., RUIZ, J. M., TROUSSE, F. and BOVOLENTA, P. (2005). Morphogens as growth cone signalling molecules. Brain Res Brain Res Rev 49: 242-252.

SARRAS, M. P. J. (2012). Components, structure, biogenesis and function of the Hydra extracellular matrix in regeneration, pattern formation and cell differentiation. Int J Dev Biol 56: 567-576.

SIEBERT, S., THOMSEN, S., REIMER, M. M. and BOSCH, T. C. G. (2005). Control of foot differentiation in Hydra: Phylogenetic footprinting indicates interaction of head, bud and foot patterning systems. Mech. Dev. 122: 998-1007.

SMITH, K. M., GEE, L., BLITZ, I. L. and BODE, H. R. (1999). CnOtx, a member of the Otx gene family, has a role in cell movement in hydra. Dev. Biol. 212: 392-404.

SMITH, K. M., GEE, L. and BODE, H. R. (2000). HyAlx, an aristaless-related gene, is involved in tentacle formation in hydra. Development 127: 4743-4752. 
SPRINZAK, D., LAKHANPAL, A., LEBON, L., GARCIA-OJALVO, J. and ELOWITZ, M. B. (2011). Mutual inactivation of Notch receptors and ligands facilitates developmental patterning. PLoS Comput Biol 7: e1002069.

SPRINZAK, E., COKUS, S. J., YEATES, T. O., EISENBERG, D. and PELLEGRINI, M. (2009). Detecting coordinated regulation of multi-protein complexes using logic analysis of gene expression. BMC Syst Biol 3: 115.

STEELE, R. E. (2002). Developmental signaling in Hydra: what does it take to build a "simple" animal? Dev Biol 248: 199-219.

STEELE, R.E. (2012). The Hydra genome: insights, puzzles, and opportunities for developmental biologists. Int J Dev Biol 56: 535-542.

STEELE, R. E., LIEU, P., MAI, N. H., SHENK, M. A. and SARRAS, M. P. (1996) Response to insulin and the expression pattern of a gene encoding an insulin receptor homologue suggest a role for an insulin-like molecule in regulating growth and patterning in Hydra. Dev. Genes Evol. 206: 247-259.

SUDHOP, S., COULIER, F., BIELLER, A., VOGT, A., HOTZ, T. and HASSEL, M. (2004). Signalling by the FGFR-like tyrosine kinase, Kringelchen, is essential for bud detachment in Hydra vulgaris. Development 131: 4001-11.

TAKAHASHI, T. and FUJISAWA, T. (2009). Important roles for epithelial cell peptides in hydra development. Bioessays 31: 610-619.

TAKAHASHI, T., HATTA, M., YUM, S., GEE, L., OHTANI, M., FUJISAWA, T. and BODE, H. R. (2005). Hym-301, a novel peptide, regulates the number of tentacles formed in hydra. Development 132: 2225-2234.

TECHNAU, U. and BODE, H. (1999). HyBra1, a Brachyury homologue, acts during head formation in Hydra. Development 126: 999-1010.

THOMSEN, S. and BOSCH, T. C. (2006). Foot differentiation and genomic plasticity in Hydra: lessons from the PPOD gene family. Dev Genes Evol 216: 57-68.

WITTLIEB, J., KHALTURIN, K., LOHMANN, J., ANTON-ERXLEBEN, F. and BOSCH, T. (2006). Transgenic Hydra allow in vivo tracking of individual stem cells during morphogenesis. Proc Natl Acad Sci USA 103: 6208-6211.

YU, S., BURKHARDT, M., NOWAK, M., RIES, J., PETRÁSEK, Z., SCHOLPP, S. SCHWILLE, P. and BRAND, M. (2009). Fgf8 morphogen gradient forms by a source-sink mechanism with freely diffusing molecules. Nature 461: 533-536.

ZHANG, X., BOOT-HANDFORD, R. P., HUXLEY-JONES, J., FORSE, L. N., MOULD, A. P., ROBERTSON, D. L., LILI, ATHIYAL, M. and SARRAS, M. P. (2007). The collagens of hydra provide insight into the evolution of metazoan extracellular matrices. J Biol Chem 282: 6792-6802. 


\section{Further Related Reading, published previously in the Int. J. Dev. Biol.}

Evolution of angiogenesis

Ramon Munoz-Chapuli

Int. J. Dev. Biol. (2011) 55: 345-351

An organizing region in metamorphosing hydrozoan planula larvae - stimulation of axis formation in both larval and in adult tissue Melanie Stumpf, Britta Will, Karola Wittig, Jennifer Kasper, Benjamin Fischer, Jürgen Schmich, Stefanie Seipp and Thomas Leitz Int. J. Dev. Biol. (2010) 54: 795-802

\section{Induction of reverse development in two marine Hydrozoans}

Jürgen Schmich, Yulia Kraus, Doris De Vito, Daria Graziussi, Ferdinando Boero and Stefano Piraino

Int. J. Dev. Biol. (2007) 51: 45-56

Wnt signaling in hydroid development: ectopic heads and giant buds induced by GSK-3beta inhibitors

Werner Müller, Uri Frank, Regina Teo, Ofer Mokady, Christina Guette and Günter Plickert Int. J. Dev. Biol. (2007) 51:211-220

Principles of branch formation and branch patterning in Hydrozoa Stefan Berking

Int. J. Dev. Biol. (2006) 50: 123-134

Cnidarians as a model system for understanding evolution and regeneration Brigitte Galliot and Volker Schmid Int. J. Dev. Biol. (2002) 46: 39-48

\section{Ca2+-ions and pattern control in Hydra}

Stefanie Zeretzke, Fernando Pérez, Kirsten Velden and Stefan Berking Int. J. Dev. Biol. (2002) 46: 705-710

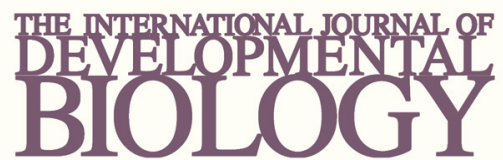

Volume 54 Nos. 6/7
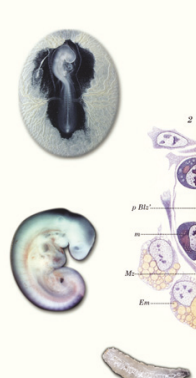

Developmental Hematopoiesis
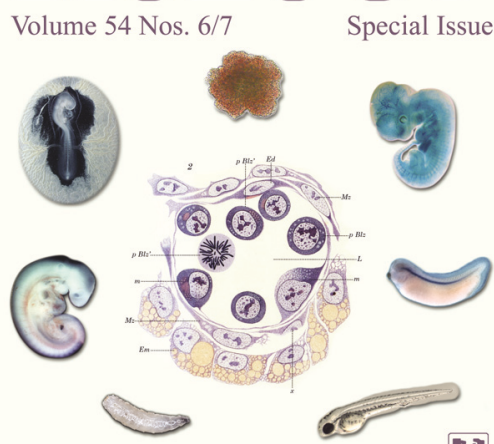

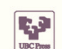

5 yr ISI Impact Factor $(2010)=2.961$
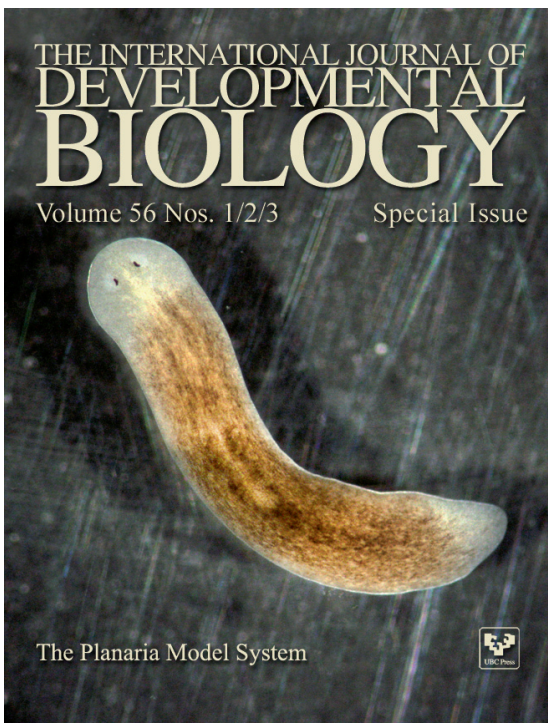
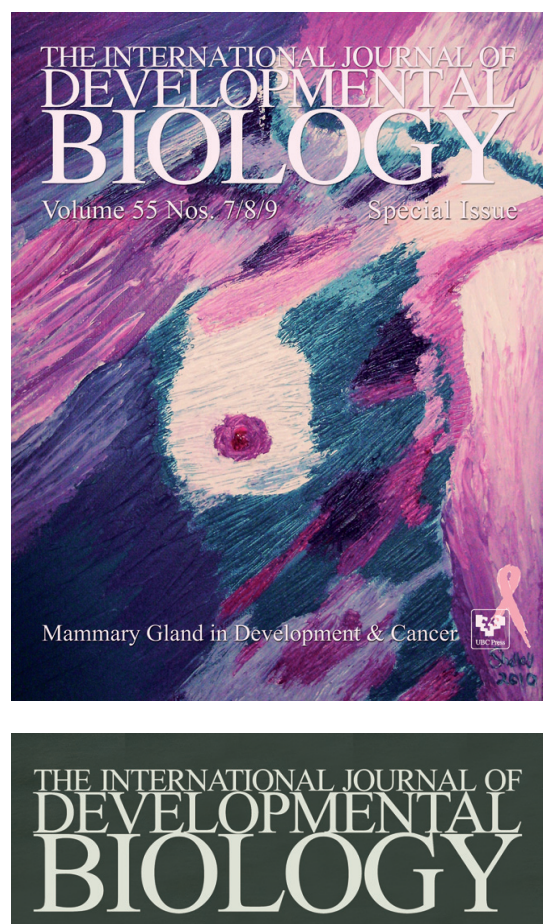

Volume 55 Nos. $4 / 5$

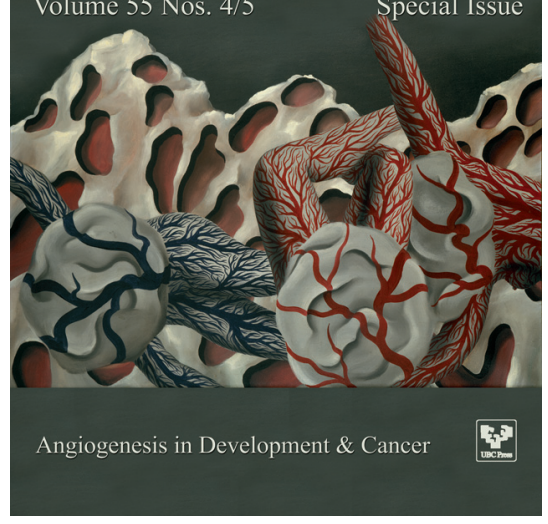

